\title{
Presepsin (SCD14-ST): Could it be a novel marker for ST-elevation myocardial infarction?
}

\section{Fatma Nihan Turhan \\ Caglar', \\ Nilgun Isiksacan², Ismail Biyik ${ }^{3}$, Ismail Ungan', \\ Selcuk Opan', \\ Hulya Cebe', \\ Ibrahim Faruk Akturk', \\ Murat Koser ${ }^{4}$, \\ Nursel Kocamaz ${ }^{* 5}$ \\ 'Department of Cardiology, Bakirkoy Dr. Sadi Konuk Education and Research Hospital, Istanbul, Turkey 2Department of Biochemistry, Bakirkoy Dr. Sadi Konuk Education and Research Hospital, Istanbul, Turkey \\ ${ }^{3}$ Department of Cardiology, Usak State Hospital, Usak, Turkey \\ ${ }^{4}$ Department of Biochemistry, Silivri State Hospital, Istanbu , Turkey \\ ${ }^{5}$ Department of İternal Medicine, Bakirkoy Dr. Sadi Konuk Education and Research Hospital, Istanbul, Turkey}

RECEIVED:

October 3, 2016

ACCEPTED:

October 10, 2016

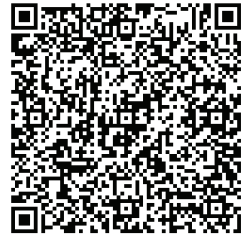

Cardiologia Croatica 2016;11(10-11):524.
KEYWORDS: myocardial infarction, presepsin, inflammation, atherosclerosis. CITATION: Cardiol Croat. 2016;11(10-11):524. | DOI: http://dx.doi.org/10.15836/ccar2016.524

*ADDRESS FOR CORRESPONDENCE: Nursel Kocamaz, Department of Internal Medicine, Bakirkoy Dr. Sadi Konuk Education and Research Hospital, Istanbul, Turkey / Phone: 0905326520670 / E-mail: nisiksacan@gmail.com

ORCID: Fatma Nihan Turhan Caglar, http://orcid.org/0000-0001-7925-2398

Nilgun Isiksacan, http://orcid.org/0000-0002-0230-6500 • Selcuk Opan, http://orcid.org/0000-0002-6335-5250

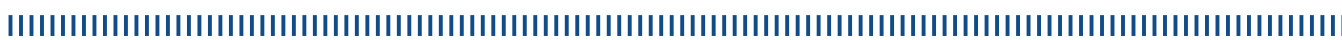
Background: Acute myocardial infarction (AMI) could be considered to be a state of inflammation. Many inflammatory markers have been evaluated during AMI setting so far. Presepsin (PSP) is a novel biomarker for diagnosis and prognosis of systemic inflammation that have not been studied in AMI setting up to date. In this study, we aimed to examine serum PSP levels in patients with acute ST elevation myocardial infarction (STEMI).

Patients and Methods: 48 patients with STEMI and fifty healthy controls without coronary artery disease, verified by coronary angiography, were included in the study. Together with routine laboratory tests needed for STEMI, plasma concentrations of PSP were measured in peripheral venous blood samples of the participants

Results: Plasma PSP and troponin levels were significantly higher in patients with STEMI than controls $(1988.89 \pm 3101.55$ vs $914.22 \pm 911.35 \mathrm{pg} / \mathrm{mL}, \mathrm{p}=0.001$ and $3.46 \pm 3.39 \mathrm{vs} 0.08 \pm 0.43 \mathrm{ng} / \mathrm{mL}, \mathrm{p}=0.001$, respectively). Cut-off value for PSP was found $447 \mathrm{pg} /$ $\mathrm{ml}$ to detect STEMI with $87.5 \%$, sensitivity, $44 \%$ specificity, $60 \%$ positive predictive value and $78.5 \%$ negative predictive value.

Conclusions: In this study, PSP levels were found significantly elevated in patients with STEMI together with high sensitive troponins. PSP may be a new marker for AMI detection. Large scale studies are needed to reveal the importance of PSP in the diagnosis of AMI. 